\title{
Spermatophore and spermatozoal morphology in the Porcellanidae. I. Aliaporcellana suluensis and Pisidia longicornis (Decapoda: Anomura: Porcellanidae)
}

\author{
Christopher C. Tudge and Barrie G. M. Jamieson
}

\begin{abstract}
An ultrastructural investigation of the porcellanid crabs, Aliaporcellana suluensis and Pisidia longicornis reveals that they possess small, spherical to ovoid, pedunculate spermatophores containing a few extremely elongate spermatozoa wound spirally inside the ampulla. In each species the ampulla is divided into two halves which join at a structurally complex, thickened lateral ridge. The spermatozoa of both species have small complex acrosomal vesicles with a perforate operculum and complex, concentric acrosome zonation. Several of these internal acrosome zones are autapomorphic characters for the spermatozoa of the Porcellanidae, when compared with previously studied anomuran spermatozoa. The elongate spermatozoa have a long tail-region composed of a central core of microtubules (autapomorphy) which has a collar of cytoplasm proximally and distally a nuclear sleeve. This central microtubular core splits distally to produce more than four external microtubular arms. The elongate, almost "flagellate", appearance of the spermatozoa of Aliaporcellana and Pisidia is unique for the investigated Decapoda.
\end{abstract}

\section{Introduction}

The historic work of Retzius (1909) provides a brief light microscope description and illustrations of the spermatophores and spermatozoa of the porcellanid, Pisidia longicornis (as Porcellana longicornis). The nearly forgotten drawings of Retzius show an elongate spermatozoon, not unlike a typically flagellate spermatozoon, capped by a small acrosomal vesicle. Although an elongate sperm form is unique in the investigated Decapoda it is found within the Crustacea in the Remipedia, Ostracoda, Ascothoracica, Mystacocarida, Pentastomida, Branchiura, Cirripedia and the Peracarida (except the Tanaidacea) (Jamieson, 1991 and references therein).

The spermatophores of Pisidia longicornis, also illustrated in Retzius (1909), have a small ovoid capsule containing the highly coiled spermatozoa. The spermatophore of $P$. longicornis is further illustrated at the light microscope level in the classic work of Mouchet (1931) on the spermatophores of anomuran and brachyuran crabs.

In the present paper, the spermatophore and spermatozoal morphology is described and illustrated for the first time for the porcellanid, Aliaporcellana suluensis. In addition, the previous light microscope investigations of Retzius (1909) for the spermatozoa of Pisidia longicornis are augmented by transmission electron micrographs of the same species. The previously described spermatophore structure of $P$. longicornis is also confirmed by light micrography.

\section{Materials and Methods}

The specimen of Aliaporcellana suluensis (Dana, 1852) was collected with the 
assistance of Queensland Department of Primary Industries, Northern Fisheries Centre, Cairns from the Turtles Group of reefs $\left(14^{\circ} 42^{\prime} \mathrm{S} 145^{\circ} 11^{\prime} \mathrm{E}\right)$, Far North Queensland, Australia in November 1992. Pisidia longicornis (Linnaeus, 1767) was collected by C. C. Tudge from waters adjacent to Laboratoire Arago, Banyuls-sur-mer $\left(42^{\circ} 29^{\prime} \mathrm{N} 3^{\circ} 08^{\prime} \mathrm{E}\right)$, France in May 1992.

The male reproductive material (testes and vasa deferentia) was removed from fresh crab specimens and immediately fixed in cold glutaraldehyde for transmission electron microscopy. Fixed spermatophores were smeared onto microscope slides and viewed and photographed by light microscopy. The specimen of Aliaporcellana suluensis was fixed in cold glutaraldehyde for a minimum of 2 hours at $4^{\circ} \mathrm{C}$ then posted to Brisbane at ambient temperature where the remainder of the fixation and embedding process was carried out.

\section{Light Microscopy}

For light microscopy, glutaraldehydefixed sperm and spermatophores were viewed and photographed under an Olympus BH2 Nomarski interference contrast microscope. Micrographs were taken with either an attached Olympus OM-2 camera or an Olympus C-35AD-4 camera operated by an Olympus Model PM-10AD photomicrographic system.

\section{Transmission Electron Microscopy}

The gonad tissue of Aliaporcellana suluensis was processed in the Zoology Department, The University of Queensland, by the standard fixation procedure (outlined below) for transmission electron microscopy. This was carried out in a Lynx -el. Microscopy Tissue Processor, after the initial glutaraldehyde fixation and first phosphate buffer wash. The specimen of Pisidia longicornis was processed by a more traditional manual method in the Laboratoire de Biologie
Parasitaire, Protistologie and Helminthologie, Muséum National d'Histoire Naturelle, Paris, as follows.

Portions of the testis (approximately 1 $\mathrm{mm}^{3}$ ) were fixed in $3 \%$ glutaraldehyde in $0.2 \mathrm{M}$ phosphate buffer ( $\mathrm{pH} 7.2$ ), with 1 $3 \%$ sucrose added, for a minimum of $1 \mathrm{~h}$ at $4^{\circ} \mathrm{C}$. They were washed in phosphate buffer ( 3 washes in $15 \mathrm{~min}$ ), postfixed in phosphate buffered $1 \%$ osmium tetroxide for $80 \mathrm{~min}$; similarly washed in buffer and dehydrated through ascending concentrations of ethanol (40-100\%). After being infiltrated and embedded in Spurr's epoxy resin (Spurr, 1969), thin sections (500-800 ^ thick) were cut on a LKB 2128 UM IV microtome with a diamond knife. Sections were placed on carbon-stabilized colloidin-coated $200 \mu \mathrm{m}$ mesh copper grids and stained (according to Daddow, 1986) in Reynold's lead citrate (Reynolds, 1963) for $30 \mathrm{~s}$, rinsed in distilled water, then $6 \%$ aqueous uranyl acetate for $1 \mathrm{~min}$, Reynold's lead citrate again for $30 \mathrm{~s}$ and a final rinse in distilled water. Micrographs were taken on an Hitachi $\mathrm{H}-300$ transmission electron microscope at $80 \mathrm{kV}$ and a JEOL 100-S transmission electron microscope at $60 \mathrm{kV}$.

\section{Results}

\section{Family Porcellanidae}

\section{Aliaporcellana suluensis}

\section{Spermatophore Morphology}

The spermatophores of Aliaporcellana suluensis are small structures $(15.3 \mu \mathrm{m}$ in total length) and are composed of an ovoid ampulla (12.5 $\mu \mathrm{m}$ long x $6 \mu \mathrm{m}$ wide) attached to a pedestal by a short, thin stalk (Fig. 2F). The ampulla has a conspicuous, raised lateral ridge around its edge which has a complex structure (Fig. 2G).

Transmission electron micrographs of the entire spermatophores show the elongate spermatozoa to be wound inside the ampulla with large amounts of extracellu- 


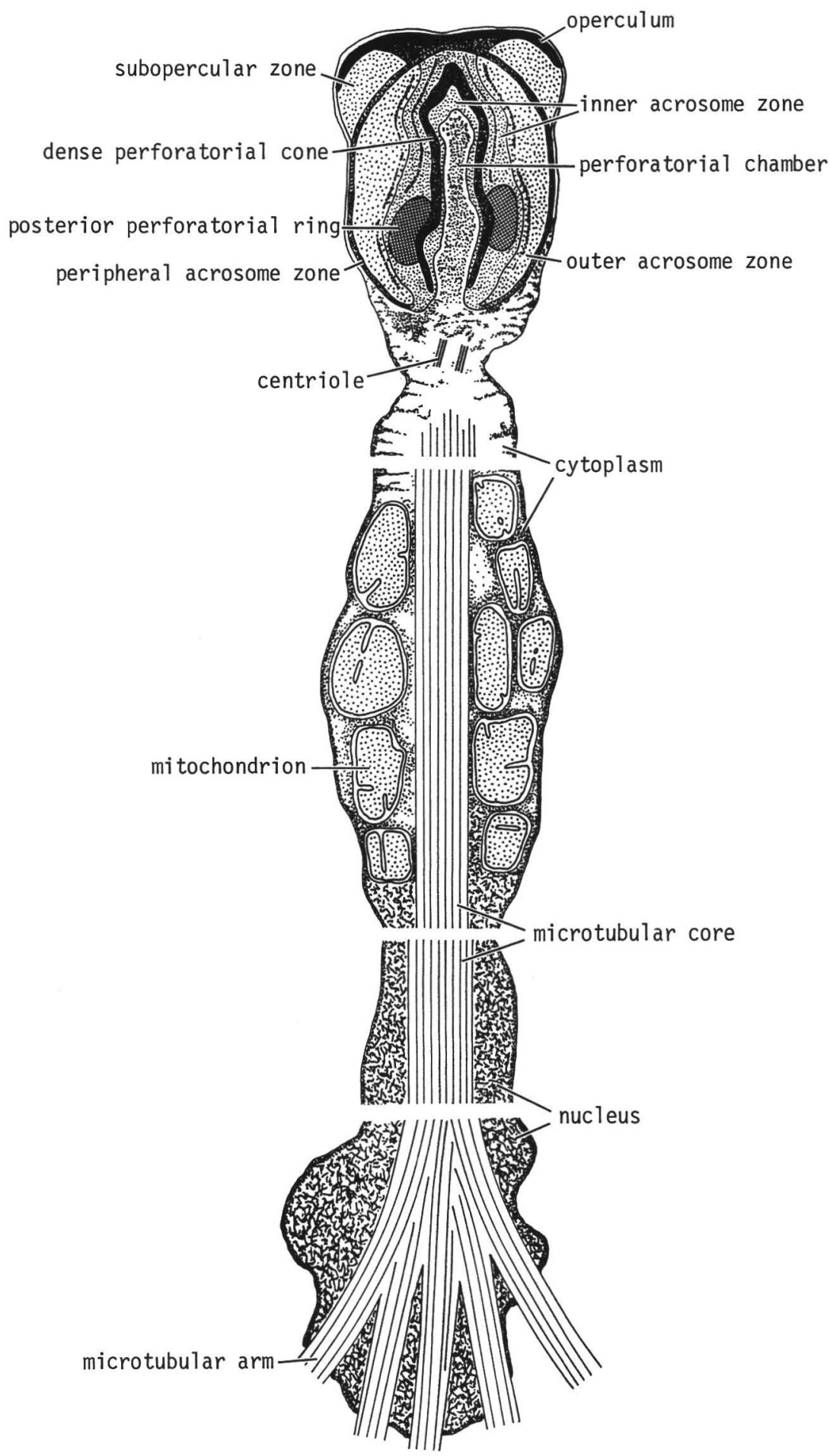

Fig. 1. Aliaporcellana suluensis (Porcellanidae). Semidiagrammatic longitudinal section of a spermatozoon, drawn from several micrographs. Scale bar $=1 \mu \mathrm{m}$. 
lar material intervening between the spermatozoa and between the spermatozoa and the ampulla wall (Fig. 2F). Micrographs of the spermatophore wall show that it is composed of an electron-dense, homogeneous, granular matrix. The raised ridge has a complex ultrastructure (Fig. 2G). The spermatophore wall increases in width at the ridge and the two halves of the ampulla are prevented from abutting on one another by the intervention of an electron-pale, heterogeneously granular intrusion. This intrusion extends from the innermost boundary of the ridge, adjacent to the extracellular material, to slightly protrude from the exterior surface. In longitudinal section the interior portion of the intrusion is bulbous, being laterally expanded, and has the appearance of an electron-dense reticulate pattern. The matrix of the ampullar wall, near to the outer surface of the ridge, has an electron-pale region on either side of the intrusion. In longitudinal section these regions appear as pale lacunae (Fig. $2 G)$.

\section{Spermatozoal Morphology}

The sperm cells of this porcellanid crab are unusual in being extremely elongate and therefore superficially resembling a typically flagellate spermatozoon, at the light microscope level. A small ovoid acrosomal vesicle ( $1.6 \mu \mathrm{m}$ long $\mathrm{x} 1.2 \mu \mathrm{m}$ wide) is present at the anterior end of the spermatozoon followed by a long, posteriorly projecting "tail" composed of cytoplasm, nucleus and microtubules (refer to Figs. 1, $2 \& 3$ throughout). Several thin, microtubular arms (the exact number could not be determined) branch out from the posteriormost tip of the cell. It is very difficult to measure the length of these elongate sperm cells but it can be ascertained that they are greater than $20 \mu \mathrm{m}$ in length.

Acrosome. The basically ovoid acrosomal vesicle is a complex, concentrically zoned structure. Anteriorly it is capped by a broad, electron-dense operculum, which is thin, probably centrally perforate, and covers the entire width of the flat topped acrosomal vesicle (Figs. 2A, 3A). Directly beneath the operculum is a subopercular zone which is in the form of an antero-lateral swelling around the top of the remainder of the ovoid acrosomal vesicle. The subopercular zone is finely granular and of moderate electron density with a denser area toward the centre of the vesicle (Figs. 2A, 3A). An inner acrosome zone surrounds the perforatorial chamber as a cylinder and extends from the subopercular zone to the base of the acrosomal vesicle. This inner zone is more electron-dense than the subopercular zone and three separate substructures can be observed within it (Figs. 2A, 3A-C). Extending anteriorly from the posterior end of the vesicle to a subterminal position is an electron-dense cone of material. This dense perforatorial cone is thin and follows the contours of the irregularly shaped perforatorial chamber (Figs. 2A, 3A-C). Adjacent to the dense perforatorial cone, near its posterior end, is a small ring of dense material, here termed the posterior perforatorial ring, which may be difficult to discern as it is of very similar electron density to the rest of the inner acrosome zone (Figs. 2A, 3C). In the anterior region of the inner acrosome zone, above the posterior perforatorial ring, some concentric layers are visible between the dense perforatorial cone and the exterior boundary of the inner acrosome zone. These few onion-like layers are visible in both transverse (Fig. 3A-C) and longitudinal sections (Fig. 2A) of the acrosomal vesicle. External to the inner acrosome zone is the outer acrosome zone. This latter zone is of similar granularity to the inner acrosome zone but is less electron-dense and fills the remainder of the acrosomal vesicle except for a thin peripheral layer which occurs immediately beneath the acrosomal vesicle membrane. Both the outer acrosome zone and this pe- 


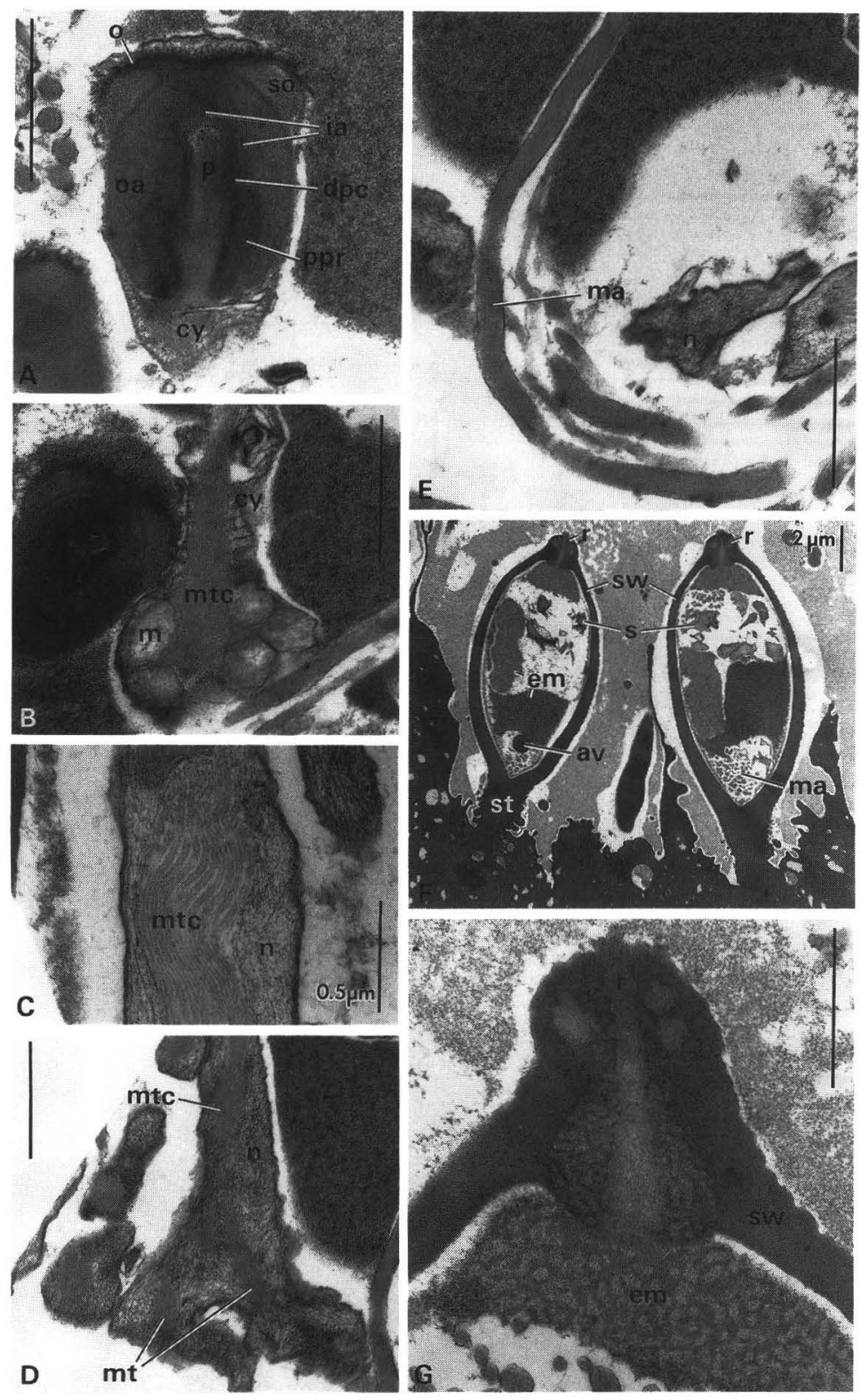

Fig. 2. Aliaporcellana suluensis (Porcellanidae). (A-G). Transmission electron micrographs of spermatozoa and spermatophores. A. Longitudinal section (LS) of acrosomal vesicle of a spermatozoon. Note: the operculum appears to be undergoing a partial reaction. B. LS of mitochondrial region. C. LS of microtubular core surrounded by nucleus. D. LS of region of splitting of microtubular core into numerous microtubular arms. E. LS of microtubular arms. F. LS of two spermatophores. Note: conspicuous lateral ridge. G. Detail of LS of spermatophore lateral ridge. av, acrosomal vesicle; cy, cytoplasm; dpc, dense perforatorial cone; em, extracellular matrix; ia, inner acrosome zone; $\mathrm{m}$, mitochondrion; $\mathrm{ma}$, microtubular arm; $\mathrm{mt}$, microtubules; mtc, microtubular core; $n$, nucleus; $\mathrm{o}$, operculum; oa, outer acrosome zone; $\mathrm{p}$, perforatorial chamber; ppr, posterior perforatorial ring; r, lateral ridge; s, spermatozoa; so, subopercular zone; st, stalk; sw, spermatophore wall. Scale bars $=1 \mu \mathrm{m}$, except where indicated. 

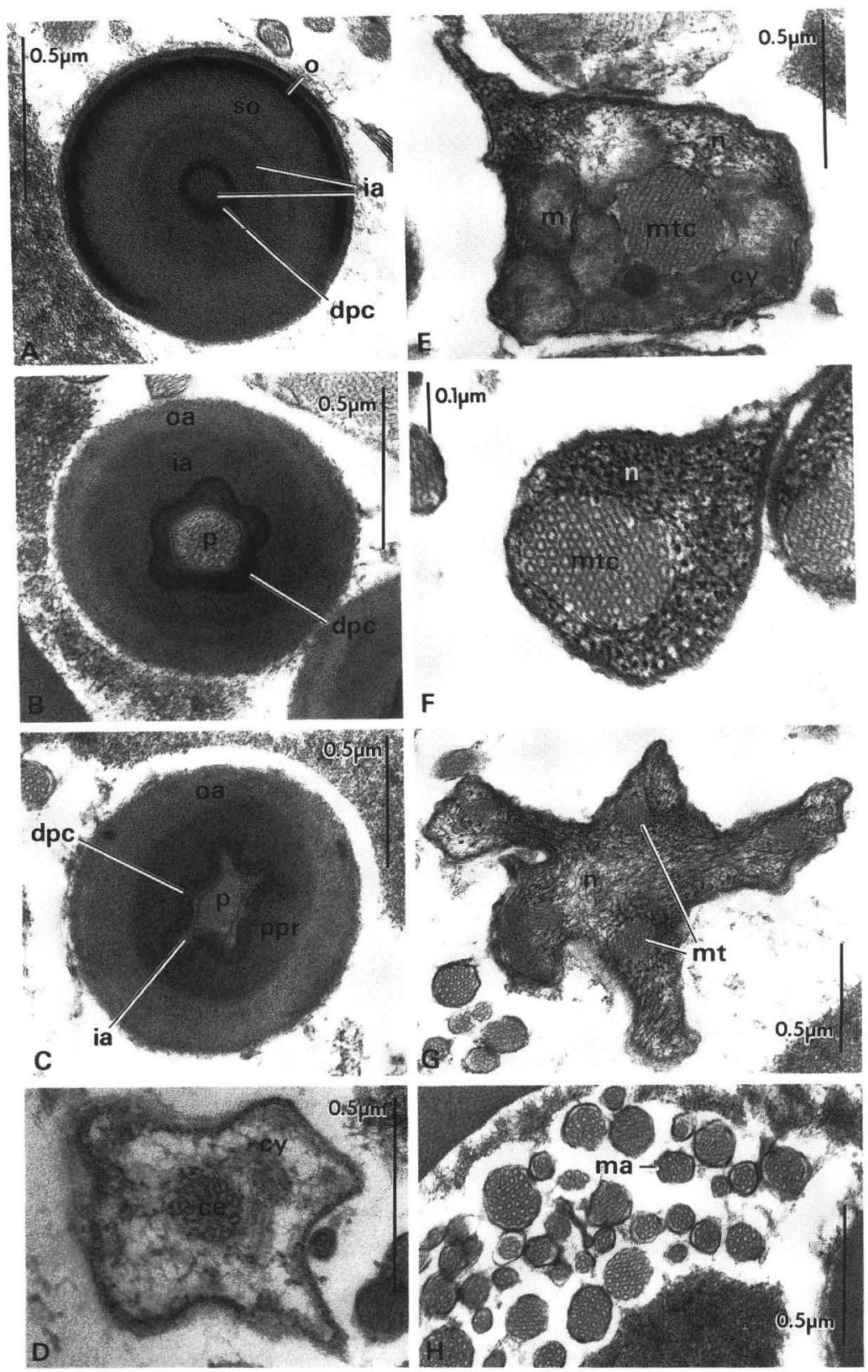

Fig. 3. Aliaporcellana suluensis (Porcellanidae). (A-H). Transmission electron micrographs of spermatozoa. A-C. Transverse sections (TS's) through the acrosomal vesicle at the level of the operculum (A) and the inner acrosome zone (B \& C). D-H. TS's through spermatozoa at the level of the centriole (D), the mitochondrial region (E), the single microtubular core and nucleus (F), the splitting of the microtubular core into microtubular arms $(G)$ and external microtubular arms (H). ce, centriole; cy, cytoplasm; dpc, dense perforatorial cone; ia, inner acrosome zone; m, mitochondrion; ma, microtubular arm; mt, microtubules; mtc, microtubular core; $\mathrm{n}$, nucleus; $\mathrm{o}$, operculum; oa, outer acrosome zone; p, perforatorial chamber; ppr, posterior perforatorial ring; so, subopercular zone. Scale bars as indicated. 
ripheral acrosome zone extend from the basal opening of the perforatorial chamber anteriorly to abut on the posterior edge of the subopercular zone. The peripheral acrosome zone forms a conspicuous, moderately electron-dense band which encircles the ovoid part of the acrosomal vesicle posterior to the subopercular and opercular regions (Figs. 2A, 3B, C).

Although the perforatorial chamber appears irregular in outline in longitudinal section (Fig. 2A), it has a roughly circular profile in transverse section (Fig. 3B), except for the posteriormost region (Fig. 3C). The perforatorial chamber penetrates the acrosomal vesicle for most of its length and bluntly terminates in the anterior quarter. The chamber contents appear finely granular and of moderate electron density, becoming more coarsely granular anteriorly.

Cytoplasmic Region. The cytoplasm in Aliaporcellana suluensis thinly envelopes the posterior end of the acrosomal vesicle and extends posteriorly as an elongated midpiece-like region (Figs. 2A, B, 3E). Immediately subjacent to the basal opening of the perforatorial chamber a single longitudinally orientated centriole (presumably one of a pair) was observed (Fig. 3D). The centriole appeared to be composed of a ring of nine doublets. In the region of the centriole the matrix of the cytoplasm is very electron lucent and heterogeneously granular with some ladder-like arrangements of membranes (Fig. 2A, B). Posterior to the centriole a large bundle of longitudinally arranged and centrally orientated microtubules originates. This microtubular core passes through the remainder of the elongate sperm cell (Figs. $2 \mathrm{~B}-\mathrm{D}, 3 \mathrm{E}, \mathrm{F})$. This microtubular core is approximately $0.4 \mu \mathrm{m}$ wide nearest the centriole and appears to increase to 0.5 $\mu \mathrm{m}$ posteriorly before splitting into several bundles and exiting from the nuclear material as independent microtubular arms (Figs. 2D, E, 3G, H). The cytoplasm increases in width below the centriolar level and contains many large, acristate mitochondria. These mitochondria which surround the microtubular core (usually only one or two deep) appear partially degenerate. They extend posteriorly for approximately $3 \mu \mathrm{m}$ before giving way to the nuclear material (Figs. 2B, 3E). The width of the cytoplasm at the level of the mitochondria is $1.2 \mu \mathrm{m}$.

Nuclear Material. The nuclear material surrounds the $0.4-0.5 \mu \mathrm{m}$ wide microtubular core as a thin veneer which extends from the cytoplasmic region to where the microtubular core separates to form several arms (Figs. 2C-E, 3E-H). The length of the nuclear region is undetermined but it must constitute a large proportion of the sperm cell. The nucleus is composed of tightly packed, anastomosing, electron-dense fibres and is surrounded by a thickened nucleo-plasma membrane (Figs. 2C, D, 3F, G).

\section{Pisidia longicornis}

\section{Spermatophore Morphology}

The spermatophores of Pisidia longicornis are small spherical structures (43 $\mu \mathrm{m}$ long) composed of a sperm-filled ampulla attached to an extremely short, almost non-existent, stalk (Fig. 5A). The ampulla which is $38 \mu \mathrm{m}$ long $\mathrm{x} 37 \mu \mathrm{m}$ wide is slightly laterally flattened forming a thickened ridge at its edge. This lateral thickening may indicate the presence of a lateral ridge, but this has not been confirmed ultrastructurally. The remainder of the spermatophore wall is thin, being about 3-3.5 $\mu \mathrm{m}$ in thickness. The spermatozoa are unusually elongate and a few (approximately six) are spirally wound inside each ampulla (Fig. 5A).

\section{Spermatozoal Morphology}

The spermatozoa are elongate cells with a small acrosomal vesicle $(1.6 \mu \mathrm{m}$ long $x 1 \mu \mathrm{m}$ wide) attached to a long, posteriorly directed "tail" composed of cyto- 
plasm and nuclear material. Although it is difficult to determine the exact size of these elongate sperm cells, it is known that they are greater than $60 \mu \mathrm{m}$ in length (Fig. 5A). The acrosomal vesicle is ovoid in shape, capped by a perforate, electron-dense operculum and posteriorly penetrated by a columnar perforatorial chamber. The cytoplasmic region attaches to the posterior end of the acrosomal vesicle and forms a "midpiece" between the vesicle and the nucleus. A large, centrally arranged, longitudinally orientated bundle of microtubules forms the core of the cytoplasm and nucleus (refer to Figs. 4 \& 5 throughout). This microtubular core appears to split into an undetermined number of distinct microtubular arms upon leaving the posterior end of the nucleus.

Acrosome. The ovoid acrosomal vesicle is capped anteriorly by a thin, electrondense operculum which is perforated in the centre and extends posterolaterally (Fig. 5B, D). Immediately subjacent to the ring-like operculum is the subopercular zone which is heterogeneously granular but less dense than the operculum. This subopercular zone is also in the form of a ring as some of the inner acrosome contents protrude into the opercular perforation (Fig. 5B, D). The inner acrosome zone is composed of four distinct regions, envelopes the perforatorial chamber and occupies the majority of the vesicle contents (Fig. 5B, D, E). A homogeneous, finely granular region of moderate electron-density thinly covers the entire length of the perforatorial chamber and anteriorly projects to fill the opercular perforation. This region also extends posterolaterally as a thin cone covering the anterior regions of the inner acrosome zone. An electron-dense perforatorial cone occurs around the anterior two-thirds of the perforatorial chamber, separated from the chamber by the thin inner acrosome layer described above (Fig. 5B, D, E). This dense perforatorial cone appears open at the apex and abruptly increases its internal diameter half way down its length to produce an obvious shoulder (Fig. 5D). A large electron-dense ring of material, separated from the perforatorial chamber wall by a layer of the finely granular region of the inner acrosome zone, is found at the posterior end of the dense perforatorial cone. This posterior perforatorial ring extends posteriorly from a point near the equator of the acrosomal vesicle, and ends above the constricted base of the perforatorial chamber. Its contents are heterogeneous and electron-dense and appear as large granules arranged in an almost reticulate pattern (Fig. 5B, D). The largest region of the inner acrosome zone extends for the entire length of the perforatorial chamber, external to the three above-mentioned regions. It is of moderate electron density and can be divided at its midpoint into two areas of differing appearance. The posterior area is finely granular and homogeneous while the anterior area has many subtle, longitudinally aligned striations or layers in a finely granular matrix. The diverse inner acrosome zone is surrounded by the outer acrosome zone which extends, as a thin layer, from the apex of the perforatorial chamber to its base. This outer acrosome zone is of similar electron density to the external areas of the inner acrosome zone but is more coarsely granular (Fig. 5B, D, E). The exterior zone of the acrosomal vesicle, the peripheral acrosome zone extends from the base of the perforatorial chamber to abut on the underside of the subopercular zone (Fig. 5B, D, E).

The columnar perforatorial chamber penetrates the posterior end of the acrosomal vesicle to a subterminal, blunt point. The chamber walls are circular in transverse section in the anterior portion but they do not retain this shape posteriorly, where the walls are convoluted to form low septa. The contents of the perforatorial chamber are finely granular and electron-pale with some electron-lucent 


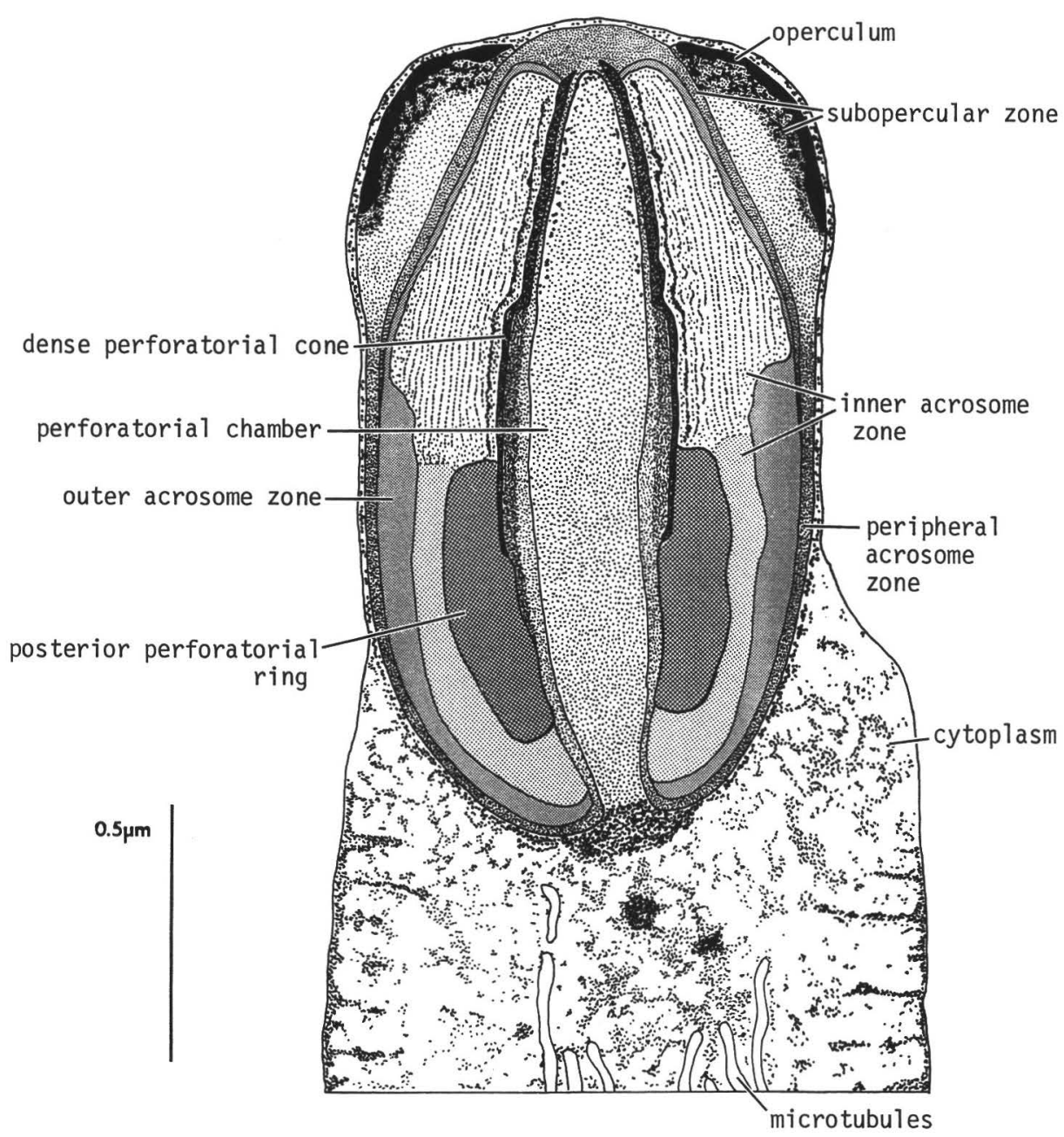

Fig. 4. Pisidia longicornis (Porcellanidae). Semidiagrammatic longitudinal section of the acrosomal vesicle of a spermatozoon, based on a tracing of a micrograph.

areas in the anteriormost tip (Fig. 5B, D).

Cytoplasmic Region. The cytoplasm cups the posterior part of the acrosomal vesicle and posteriorly has the appearance of an elongate "midpiece" between the vesicle and the nucleus. The cytoplasmic region is about $1.0-1.3 \mu \mathrm{m}$ in width and can be up to $5 \mu \mathrm{m}$ in length. In the cytoplasm adjacent to the acrosomal vesicle a series of horizontal (ladder-like) membranes occur which are attached to the inside of the cell membrane and posteriorly are associated with the few mito- chondria (Fig. 5B). The mitochondria appear to be degenerate and therefore are sometimes irregularly shaped and indistinct. A pair of centrioles was observed in the cytoplasm below the open end of the perforatorial chamber and associated with the anterior end of the microtubular core. The conspicuous microtubular core extends for the full length of the sperm cell except for the acrosomal vesicle and is a tight assemblage of longitudinally arranged microtubules with a circular cross section of approximately $0.5 \mu \mathrm{m}$. This core 


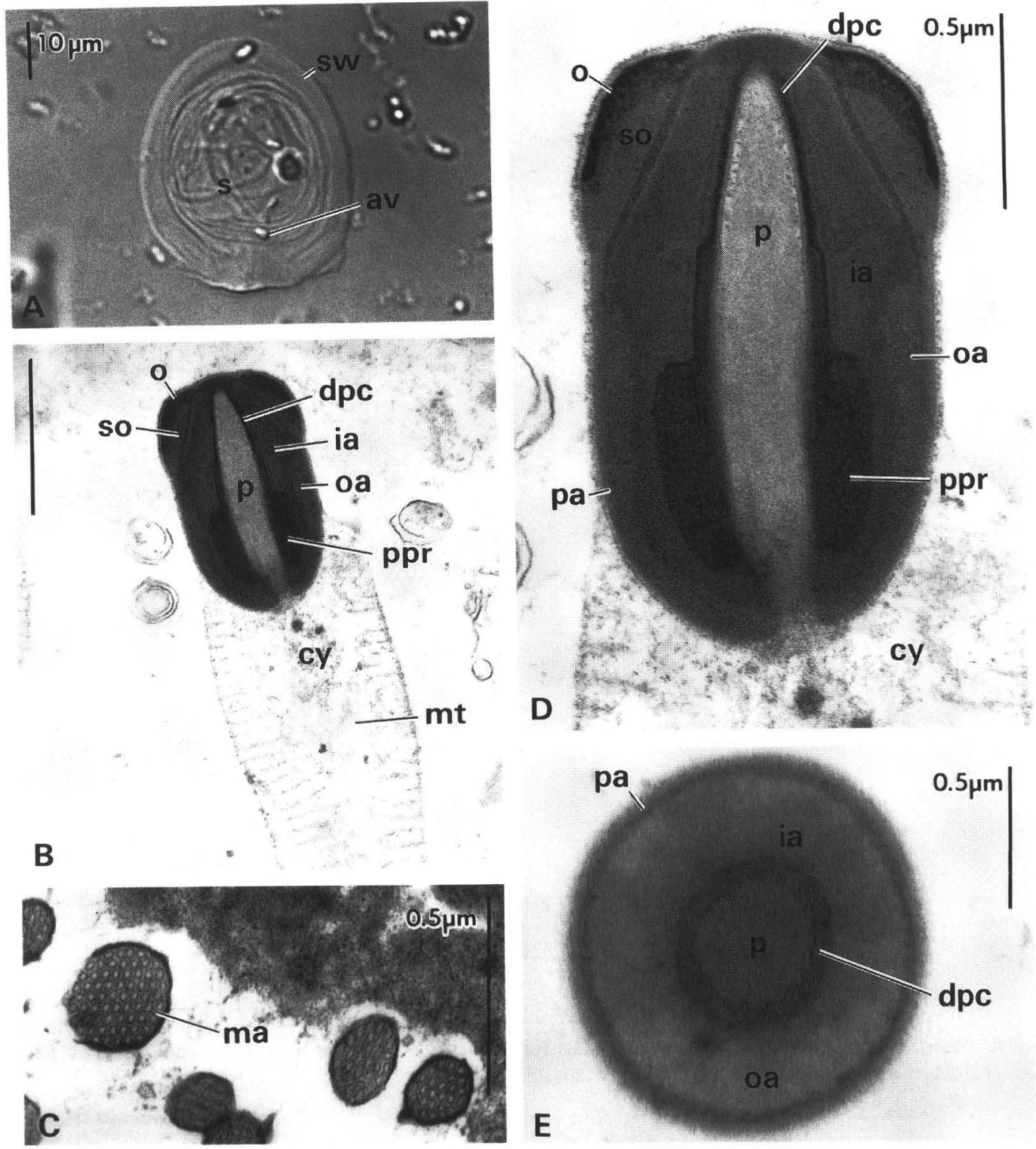

Fig. 5. Pisidia longicornis (Porcellanidae). (A-E). Light and transmission electron micrographs of spermatozoa and spermatophores. A. Light micrograph of a spermatophore showing elongate spermatozoa spirally arranged inside. B. Longitudinal section (LS) of acrosomal vesicle and cytoplasmic region of a spermatozoon. C. Transverse section (TS) of microtubular arms. D. Detail of LS of acrosomal vesicle. E. TS of acrosome at the level of the dense perforatorial cone. av, acrosomal vesicle; cy, cytoplasm; dpc, dense perforatorial cone; ia, inner acrosome zone; ma, microtubular arm; mt, microtubules; o, operculum; oa, outer acrosome zone; p, perforatorial chamber; pa, peripheral acrosome zone; ppr, posterior perforatorial ring; s, spermatozoa; so, subopercular zone; sw, spermatophore wall. Scale bars $=1 \mu \mathrm{m}$, except where indicated. 
of microtubules appears to emerge from the nucleus as a single bundle and posteriorly separates into smaller, membrane bound microtubular arms (Fig. 5C).

Nuclear Material. The nucleus continues posteriorly from the cytoplasmic region as a thin sleeve of material around the microtubular core. The width of the nucleus varies from just greater than 1 $\mu \mathrm{m}$ adjacent to the cytoplasm to $0.6 \mu \mathrm{m}$ near its posteriormost end. It is not known how far the nucleus extends along the length of the sperm cell but ultimately it terminates leaving the microtubular core surrounded by a cellular membrane. The nucleus consists of electron-dense, anastomosing fibres on an electron-lucent background and is surrounded by a thickened membrane.

\section{Discussion}

In Aliaporcellana suluensis and Pisidia longicornis the pedunculate spermatophores are small and spherical to ovoid in shape with the few elongate spermatozoa spirally wound inside the ampulla (Figs. 2F, 5A). This spermatophore morphology differs greatly from another investigated porcellanid genus Petrolisthes (Tudge \& Jamieson, 1996), where the anterior end of the ampulla is drawn out into a long, tubular extension. All three genera possess pedunculate spermatophores, which characterise the infraorder Anomura (Tudge, 1995a).

Mouchet (1931) showed that the spermatophores of Pisidia longicornis possessed a lateral ridge where the ampulla split to release the spermatozoa. This lateral ridge may be apparent in Fig. 5A as the thickened spermatophore wall. Transmission electron microscopy of the spermatophore of Aliaporcellana suluensis (Fig. 2F, G) reveals that it also possesses a lateral ridge and that it is ultrastructurally complex. This lateral ridge has been recorded in 27 species from five anomuran families (Tudge, 1991, 1995a) and, like the pedunculate spermatophore, may be characteristic for the Anomura.

The spermatozoa of Aliaporcellana suluensis and Pisidia longicornis show a particular suite of acrosomal vesicle characters which unites them. The acrosomal vesicle is superior in relation to the cytoplasm (which generally forms a thin, neck-like region) and is capped by a broad, flat, perforate operculum. The acrosomal vesicles of Aliaporcellana and Pisidia (present study), and Petrolisthes (Jamieson, 1991; Tudge \& Jamieson, 1996) and Polyonyx (Tudge \& Jamieson, 1996), have the smallest recorded dimensions in the Anomura studied to date (Tudge, 1995a). The perforate operculum (common to all four porcellanid genera) has previously been seen in the Anomura, only in the spermatozoon of the diogenid hermit crab, Cancellus sp. (Tudge, 1995a, b). The wall of the perforatorial chamber in the spermatozoa of Aliaporcellana and Pisidia is variously folded to form broad septa and the concentric zonation of the acrosomal vesicle has three important features (Figs. 1, 2A, 3A-C, 4, 5B, D, E). These are the autapomorphic dense perforatorial cone and posterior perforatorial ring and the synapomorphic divided inner acrosome zone, which is shared with some galatheids (Tudge, 1995a).

The centriole observed in Aliaporcellana suluensis is described as composed of nine outer doublets, but it is not clear if a third (incomplete "c") tubule is present or not. There are definitely no central singlets, but some centrally projected radial links are apparent. Doublet centrioles have previously been recorded in majid crabs (Hinsch, 1973), the brachyuran, Neodorippe (Jamieson \& Tudge, 1990) and even in peracarids (Cotelli et al., 1975, 1976). Jamieson (1989) stated that a doublet centriolar structure may even be an autapomorphy of the Malacostraca.

Aliaporcellana and Pisidia have an elongate spermatozoal morphology characterised by the possession of a central core of microtubules which splits, posteri- 
orly, to form several microtubular arms. Although it is often difficult to ascertain the exact number of microtubular arms in the spermatozoa of these porcellanids, it appears that there are four or more (definitely more than three) external microtubular arms in each species. This condition is unusual (shared with some members of the Hippoidea) in that the remainder of the investigated anomurans consistently have three microtubular arms (Tudge, 1995a). The microtubular core extends the entire length of the sperm cell, from the neck-like region of cytoplasm below the acrosomal vesicle, to the posteriormost end of the nucleus. This microtubular core is unique to these two investigated porcellanid spermatozoa and has also been recorded in the porcellanid, Polyonyx transversus (see Tudge \& Jamieson, 1996). This is not unexpected as Aliaporcellana suluensis was previously assigned to the genus Polyonyx (Haig, 1965).

The cytoplasm and nucleus surround the microtubular core and form a thin veneer for most of its length. The midpiecelike arrangement of the cytoplasm, forming a mitochondrial sleeve, adds to the elongate spuriously "flagellate" appearance of the sperm cells and contrasts markedly with all other investigated anomuran crab spermatozoa. In the latter the cytoplasm forms a cup-like region around the base of the acrosomal vesicle and the majority of the mitochondria and other organelles are concentrated as a lateral ring (Hinsch, 1980, 1991; Tudge \& Jamieson, 1991; Tudge, 1992, 1995a,b).

Live spermatozoa were not observed outside of the spermatophore of Aliaporcellana or Pisidia, and so it cannot be confirmed that the microtubular core and arms are immotile. An assumption of immotility is based on the fact that the microtubular core and arms are composed of tight bundles of single microtubules with no fixed arrangement or substructure. No dynein arms are present. This lack of dynein arms precludes that flagellar bending activity cannot occur via the standard sliding filament model. Similar bundles of microtubules make up the arms or spikes of other anomuran crabs (Tudge, 1995a,b), astacideans and palinurans (Jamieson, 1991) and some brachyurans (Hinsch, 1973; Jamieson, 1991), in which no motility has yet been observed.

Ultrastructural investigations of the spermatozoa and spermatophores of Aliaporcellana suluensis and Pisidia longicornis confirm the unusual sperm cell structure illustrated for $P$. longicornis by Retzius (1909). The flagellate appearance of the spermatozoa of these two porcellanids (and also Polyonyx transversus (see Tudge \& Jamieson, 1996)) is so far unique to this family among all the investigated decapods. Further studies of spermatozoal ultrastructure in other genera in the Porcellanidae will investigate how conservative this sperm morphology is within the family.

\section{Acknowledgments}

The authors wish to thank QDPI Cairns, Northern Fisheries Centre (in particular Dr. Neil Gribble and the helpful crew of the "Gwendolyn May") for assistance in the collection of the specimen of Aliaporcellana suluensis. Similarly for the collection of Pisidia longicornis, we thank the Director and staff of the Laboratoire Arago, Banyuls-sur-Mer, France. The collection of $P$. longicornis was made possible by CCT receiving a French Government Scientific Fellowship for 1992 which enabled him to work at the Muséum National d'Histoire Naturelle, Paris. Prof. Joseph Schrével and Dr. Jean-Lou Justine (Laboratoire de Biologie Parasitaire, Protistologie et Helminthologie) are thanked for providing the facilities for the initial fixation of $P$. longicornis.

Mrs. Lina Daddow (Zoology Department, The University of Queensland) is 
heartily thanked for expert assistance with all aspects of electron microscopy. The authors are also grateful to Prof. Danièle Guinot (MNHN, Paris) and Mr. Peter Davie (Queensland Museum) for identification of the specimens.

\section{Literature Cited}

Cotelli, F., Ferraguti, M., Lanzavecchia, G., \& Lora Lamia Donin, C., 1976. The spermatozoon of the Peracarida. I. The spermatozoon of terrestrial isopods. Journal of Ultrastructure Research, 55: 378-390.

, - \& Lora Lamia Donin, C., 1975. An unusual centriolar pattern in Isopoda sperm cells. Journal of Submicroscopic Cytology, 7: 289-292.

Daddow, L. Y. M., 1986. An abbreviated method of the double lead stain technique. Journal of Submicroscopic Cytology, 18: 221-224.

Haig, J., 1965. The Porcellanidae (Crustacea, Anomura) of Western Australia with descriptions of four new Australian species. Journal of the Royal Society of Western Australia, 48: 97-118.

Hinsch, G. W., 1973. Sperm structure of Oxyrhyncha. Canadian Journal of Zoology, 51: 421-426.

$\longrightarrow, 1980$. Spermiogenesis in Coenobita clypeatus, I. Sperm structure. International Journal of Invertebrate Reproduction, 2: 189-198.

- 1991. Ultrastructure of the sperm and spermatophores of the anomuran crab Pleuroncodes planipes. Journal of Crustacean Biology, 11: 17-22.

Jamieson, B. G. M., 1989. A comparison of the spermatozoa of Oratosquilla stephensoni and Squilla mantis (Crustacea, Stomatopoda) with comments on the phylogeny of the Malacostraca. Zoologica Scripta, 18: 509-517.

$\longrightarrow, 1991$. Ultrastructure and phylogeny of crustacean spermatozoa. Memoirs of the Queensland Museum, 31: 109-142.

$\longrightarrow, \&$ Tudge, C. C., 1990. Dorippids are Heterotremata: evidence from ultrastructure of the spermatozoa of Neodorippe astuta (Dorippidae) and Portunus pelagicus (Portunidae) Brachyura: Decapoda. Marine Biology, 106: 347-354.

Mouchet, S., 1931. Spermatophores des Crustacés Décapodes Anomoures et Brachyoures et castration parasitaire chez quelques Pagures. Station Océanographique de Salammbô, Annales, 6: 1203.

Retzius, G., 1909. Die spermien der Crustaceen. Biologische Untersuchungen, 14: 1-54.

Reynolds, E. S., 1963. The use of lead citrate at high $\mathrm{pH}$ as an electron opaque stain in electron microscopy. Journal of Cell Biology, 17: 208-212.

Spurr, A. R., 1969. A low viscosity epoxy-resin embedding medium for electron microscopy. Journal of Ultrastructure Research, 26: 31-43.

Tudge, C. C., 1991. Spermatophore diversity within and among the hermit crab families, Coenobitidae, Diogenidae and Paguridae (Paguroidea, Anomura, Decapoda). Biological Bulletin, 181: 238-247.

-1992 . Comparative ultrastructure of hermit crab spermatozoa (Decapoda: Anomura: Paguroidea). Journal of Crustacean Biology, 12: 397-409.

- , 1995a. The Ultrastructure and Phylogeny of Anomuran Crab Spermatozoa. PhD. Thesis. Zoology Department, The University of Queensland, Australia. pp. 1-346.

$-1995 \mathrm{~b}$. Ultrastructure and Phylogeny of the Spermatozoa of the Infraorders Thalassinidea and Anomura (Decapoda, Crustacea). In: B.G.M. Jamieson, J. Ausio \& J.-L. Justine (eds.), Advances in Spermatozoal Phylogeny and Taxonomy. Mémoires du Muséum National d'Histoire Naturelle (Paris), 166: 251-263.

-, \& Jamieson, B. G. M., 1991. Ultrastructure of the mature spermatozoon of the coconut crab Birgus latro (L.) (Coenobitidae, Paguroidea, Decapoda). Marine Biology, 108: 395-402.

$\longrightarrow, \&-, 1996$. Spermatophore and spermatozoal morphology in the Porcellanidae. II. The genera Petrolisthes and Polyonyx (Decapoda, Anomura, Porcellanidae). Journal of Crustacean Biology, 16(3): 535-546.

Addresses: (CCT) Department of Invertebrate Zoology, National Museum of Natural History, Smithsonian Institution, Washington D.C. 20560, USA; (BGMJ) Zoology Department, The University of Queensland, Brisbane Q4072, Australia.

E-mails: (CCT) ctudge@mov.vic.gov.au; (BGMJ) b.jamieson@mailbox.uq.oz.au 